\title{
Realization of optical fibers terminated with ball lenses
}

\author{
B. GUZOWSKI*, Z. LISIK and G. TOSIK \\ Technical University of Lodz, Dept. of Semiconductor and Optoelectronics Devices, 211/215 Wolczanska St., 90-924 Lodz, Poland
}

\begin{abstract}
In this article the process of realization of ball-lensed optical fibers is described. The implementation of four different types of balllensed optical fibers developed in Optical Fibers Techniques Laboratory at Lodz University of Technology is presented. Focal lengths of the presented microlenses, which were obtained in simulations and measurements, are also shown in this paper.
\end{abstract}

Key words: microlens, coupling, optical fiber, active elements.

\section{Introduction}

Maintaining the pace of development of integrated circuits is owed to multi-chip modules (MCM). They belong to a group of the most complex elements in modern electronics and the process of their production and assembly involves the use of very advanced techniques. The increase in the length of metal lines causes an undesirable increase in the parasitic elements, which makes the transmission of very high frequency signals impossible. Another limitation arising from the use of conventional electrical connections of integrated circuits is their sensitivity to electromagnetic interference, which in turn may lead to the malfunction of the entire system, in particular if we take into account that the electrical connections operating at a frequency of the order of hundreds of $\mathrm{MHz}$ or $\mathrm{GHz}$ become a source of such interference themselves. The aforementioned problems sign ificantly hinder the development of integrated circuits and cause the search for new solutions.

\section{Optical connections in chip-to-chip systems}

It is believed that replacing electrical wires with optical fibers will solve many problems such as delays, electromagnetic interference (EMI) or crosstalk, which occur in fast $(\mathrm{GHz})$ communication with the use of electrical signals. This is reflected in a number of articles [1-5] and books related to the introduction of optical interconnectors for very-large-scale integration (VLSI) circuits [6-9]. A printed circuit board (PCB) makes use of optical systems communicating with each other in free space [10]. Such systems have the particular advantage of allowing for high density and - due to the use of, e.g., controllable micromirrors - for switching a light beam [11]. However, a rather serious disadvantage of such solutions is the difficulty in coupling of the whole optical system [12]. Another method of connecting optical active elements taken into consideration is the use of glass optical fiber [13] or polymer optical fibers [14-15]. Also

*e-mail: bartlomiej.guzowski@p.lodz.pl planar waveguides [16] and the strip core optical fiber [17] are considered. Research is also conducted on mixed solutions for connections on one structure [18] using both free space transmission and the optical fiber. A number of reaserch activities [19-23] connected with integrating glass fibers in electronic cicuits are conducted. Such fibers, both single and multi-mode, are commonly used, and their mechanical processing is well known. The greatest challenge in research on integrated optical circuits based on glass fibers is coupling passive and active elements. Butt coupling method is very popular. This solution involves coupling the input or output of the fiber to the output of the laser or an input of the photodetector. However, the basic disadvantage of this method is that in order to achieve low power loss, the fiber should touch the active elements, which is not always possible. Moving the fiber away from the active elements always causes a decrease in coupling efficiency. Due to the small radius of core, in butt coupling methods lateral displacements are also higly undesirable. In order to achieve higher connection efficiency, lenses as well as micromirrors are commonly used [24-26]. By using ball-lensed optical fiber we obtain bigger numerical aperture (NA) and therefore, it is easier to couple optical fiber to active elements. Furthermore, there is no need to calibrate the lens and fiber, as is the case when lenses are separate from optical fiber.

\section{Multi-fiber expanded beam connectors}

Another application in which ball-lensed optical fibers can be used are expanded beam (EB) connectors, especially multi-fiber types such as MPO/MTP (Multiple-Fiber and Push-On/PullOff). Single-fiber expanded beam ferrules, described first by Baker [27], typically use lenses to expand and focus the light between transmitting and receiving fiber. The lenses are generally either ball lenses or graded index rod lenses (GRIN). Multi-fiber EB connectors commercially available since 2014 [28] are dedicated to cabling in data centers. EB connectors are less sensitive to dirt and due to fiber NA end face separation losses are reduced. Because lenses in EB connectors are still separate elements, coupling the whole system is much more 
complicated than in case of coupling ball-lensed fibers. Moreover, using ball-lensed optical fibers potentially reduces return losses in connector.

\section{Coupling with the use of ball lenses}

In order to achieve high efficiency of coupling multi-mode fibers, it is necessary to minimize lateral displacement and to bring the fiber as close to the active element as possible. The aforementioned conditions make the design process and implementation of integrated optical connections difficult. One of the solutions, which may facilitate the process of coupling active and passive elements, is the use of ball-lensed fibers, shown in Fig. 1. Thanks to the lens it is no longer necessary to place the fiber right next to the output of the laser or directly next to the photodetector. Due to the use of ball microlens, the active element may be placed at a certain distance from the fiber (it is best to put it in the focal of the lens), whereas the coupling efficiency will remain on a high level. The change of the diameter of the microlens involves changing its focal length. This way the distance between the fiber and the active elements can be controlled, which is a great convenience in the design of integrated optical systems.

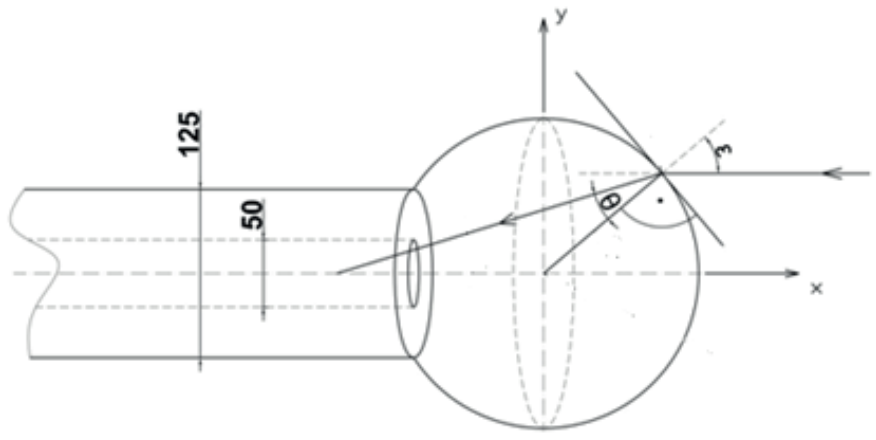

Fig. 1. The concept of ball-lensed optical fibers, where $\varepsilon-$ angle of incidence, $\theta$ - angle of refraction

\section{The realization of ball microlenses}

In the Optical Fibers Techniques Laboratory at Lodz University of Technology, four types of ball-lensed fibers were produced. The diameters of the microlenses ranged from $133 \mu \mathrm{m}$ to $230 \mu \mathrm{m}$. FITEL S153A fusion splicer by Furukawa was used in the production process. In order to produce such ball microlenses, cleaved multi-mode fiber (MMF) OM4 optical fibers were placed in the V-groove of the splicer as shown in Fig. 2 and Fig. 3. Optical fibers were put between the V-groove and the electrodes. Then, after closing the protective cover of the splicer, different diameters of ball lenses were realized by manually selecting appropriate parameters of the splicer. The most important settings are presented in Table 1.

After setting the desired parameters of the splicer and positioning the MMF fibers in relation to the electrodes, marked in Table 1 (the initial length of the fiber), two electrical discharges

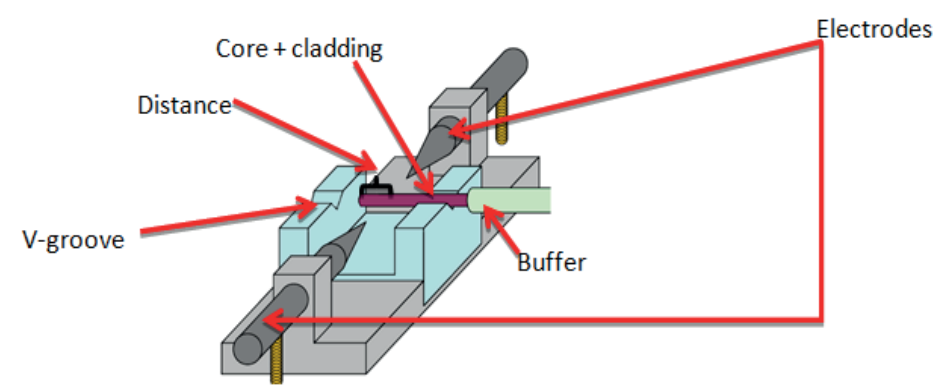

Fig. 2. Schematic of fiber alignment inside the splicer

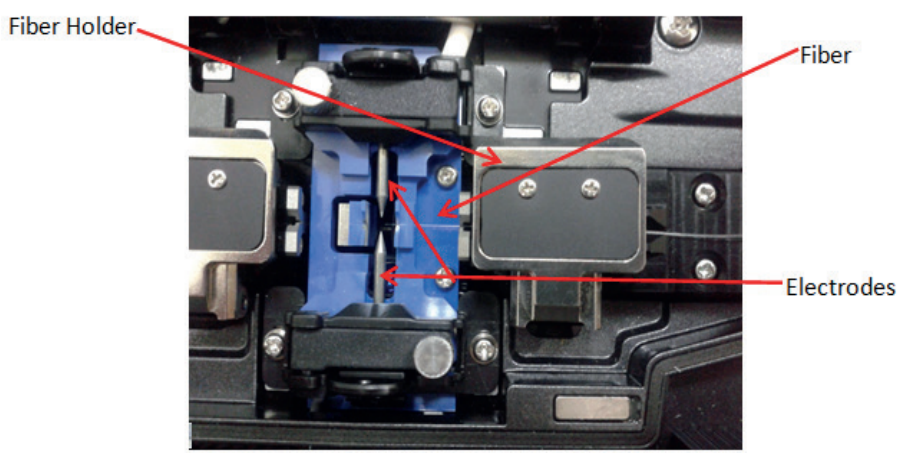

Fig. 3. A photo of the fiber placed in the splicer

of the electrodes were induced, and ball microlenses were created by melting the ends of MMF fibers. During the discharges the fiber was moved according to the parameter marked in Table 1 (the length of the fiber pushed during electrodes' electrical discharges).

Table 1

Programming parameters

\begin{tabular}{|l|c|c|c|c|}
\hline \multicolumn{5}{|c|}{ The name of the ball lens } \\
\hline \multicolumn{1}{|c|}{ Parameter } & $\begin{array}{c}\text { Ball lens } \\
\mathbf{1 3 3} \boldsymbol{\mu m}\end{array}$ & $\begin{array}{c}\text { Ball lens } \\
\mathbf{1 5 0} \boldsymbol{\mu m}\end{array}$ & $\begin{array}{c}\text { Ball lens } \\
\mathbf{2 1 5} \boldsymbol{\mu m}\end{array}$ & $\begin{array}{c}\text { Ball lens } \\
\mathbf{2 3 0} \boldsymbol{\mu m}\end{array}$ \\
\hline The diameter [ $\mu \mathrm{m}]$ & $133 \pm 4$ & $150 \pm 3$ & $215 \pm 4$ & $230 \pm 4$ \\
\hline $\begin{array}{l}\text { Discharge power of the } \\
\text { first arc [mW] }\end{array}$ & 50 & 100 & 100 & 200 \\
\hline $\begin{array}{l}\text { Time of discharging of } \\
\text { the electrodes [s] }\end{array}$ & 3 & 3 & 3 & 3 \\
\hline $\begin{array}{l}\text { Discharge power of the } \\
\text { second arc [mW] }\end{array}$ & 80 & 142 & 255 & 255 \\
\hline $\begin{array}{l}\text { The initial length of the } \\
\text { fiber [ } \mu \mathrm{m} \text { ] }\end{array}$ & 150 & 200 & 200 & 200 \\
\hline $\begin{array}{l}\text { The length of the } \\
\text { fiber pushed during } \\
\text { electrodes' electrical } \\
\text { discharges [ } \mu \mathrm{m}]\end{array}$ & 20 & 1500 & 32767 & 32767 \\
\hline
\end{tabular}

Two examples of ball lenses: ball lens $150 \mu \mathrm{m}$ and ball lens $230 \mu \mathrm{m}$, made as described above, are presented in Fig. 4. 

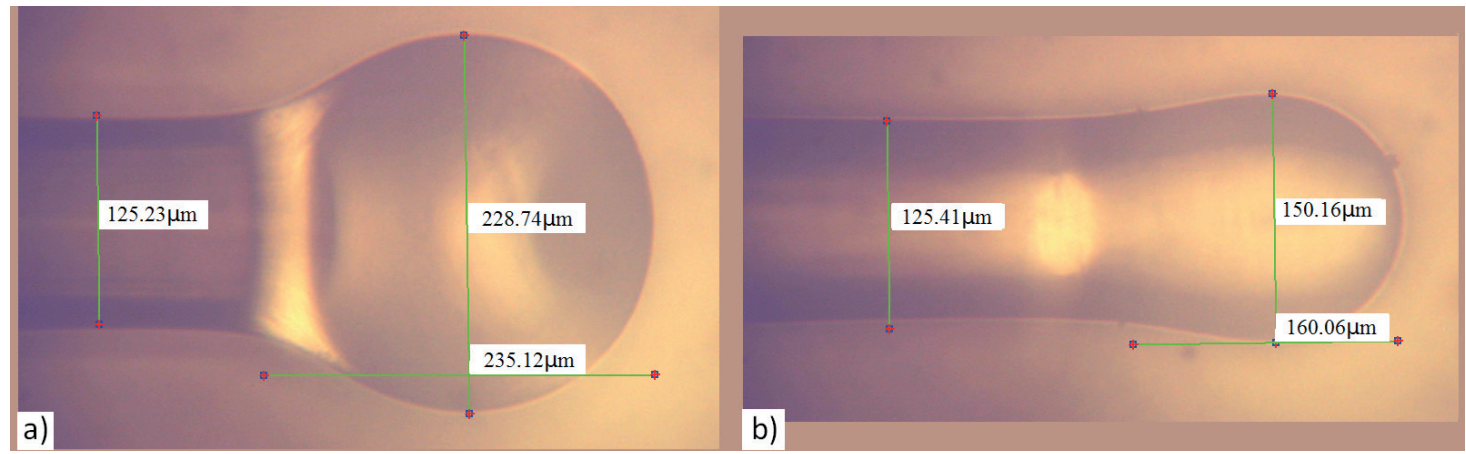

Fig. 4. Ball-lensed optical fiber: (a) diameter $230 \mu \mathrm{m}$, (b) diameter $150 \mu \mathrm{m}$

Focal lengths were designated for the performed ball lenses numerically - using the commonly available OSLO EDU [29] software for optical elements analysis, as well as an authorial software created on the MATLAB platform - and experimentally, using a measuring set consisting of a positioning platform MAX373D by Thorlabs, an optical power meter AF-ORL-3.1 and a light source AF-LST-85 of $850 \mathrm{~nm}$ wavelength.

Table 2

Comparison of focal lengths obtained in simulations and measurements

\begin{tabular}{|l|c|c|c|c|}
\hline \multirow{2}{*}{$\begin{array}{l}\text { Method of determining } \\
\text { focal lengths }\end{array}$} & \multicolumn{4}{|c|}{ Focal length of the ball microlens [ $\boldsymbol{\mu m}]$} \\
\cline { 2 - 5 } & $\begin{array}{c}\text { Ball lens } \\
\mathbf{1 3 3} \boldsymbol{\mu m}\end{array}$ & $\begin{array}{c}\text { Ball lens } \\
\mathbf{1 5 0} \boldsymbol{\mu m}\end{array}$ & $\begin{array}{c}\text { Ball lens } \\
\mathbf{2 1 5} \boldsymbol{\mu m}\end{array}$ & $\begin{array}{c}\text { Ball lens } \\
\mathbf{2 3 0} \boldsymbol{\mu m}\end{array}$ \\
\hline OSLO & 211.6 & 238.6 & 351 & 365.9 \\
\hline MATLAB & 201.19 & 228.13 & 330.25 & 353.71 \\
\hline MEASUREMENTS & 166.7 & 190.4 & 393.1 & 423.4 \\
\hline
\end{tabular}

The results are summarized in Table 2. The results of the simulations are similar, yet they are significantly different from the measurements obtained experimentally. The difference may be caused by the fact that the lenses are never an ideal ball with a constant radius. Additionally, the refractive index of the lens differs insignificantly from the refractive index of the core. Because of that, the light coming through the lens is refracted already in the lens, and not beyond it, as was assumed in the simulations.

\section{Summary}

Problems related to further development of electronic circuits, described more thoroughly in the first part of the paper, urged many research centers to conduct research on finding new conceptions of developing integrated circuits. Optical connections, as compared to electrical connections, possess many advantages connected with transmitting signals of high frequency. The problematic area in integrated optical circuits is the place of coupling the fiber with the active elements. The simplest method is butt coupling; however, it requires direct contact in order to reduce power loss. Thanks to the use of ball-lensed fibers presented in the paper, the active element may be placed at a certain distance from the fiber, while maintaining high coupling efficiency. Such a solution will facilitate introducing optical connections into integrated MCM systems.

\section{REFERENCES}

[1] Y. Takagi, A. Suzuki, T. Horio, T. Ohno, T. Kojima, T. Takada, S. Iio, K. Obayashi, M. Okuyama, "4-Ch $\times 10-\mathrm{Gb} / \mathrm{s}$ Chip-toChip Optical Interconnections With Optoelectronic Packages and Optical Waveguide Separated From PCB", CPMT Symposium Japan, ISBN: 978-1-4244-7593-3, 1-4 (2010).

[2] J-S. Youn., M-J. Lee, K-Y Park, W-Y Choi., "10-Gb/s 850-nm CMOS OEIC Receiver with a Silicon Avalanche Photodetector", J. Qantum Electronics, 48 (2), 229-236 (2012).

[3] J. Sakai, A. Noda, M. Yamagishi, T. Ohtsuka, K. Sunaga, H. Sugita, H. Takahashi, M. Oda, H. Ono, K. Yashiki, H. Kouta, "20Gbps/ch Optical Interconnection between SERDES Devices over Distances from Chip-to-Chip to Rack-to-Rack", European Conf. on Optical Communication ECOC 2008, ISBN:978-14244-2227-2, 1-2 (2008).

[4] B. Moore, C. Sellathamby, S. Slupsky, K. Iniewski, "Chip to Chip Communications for Terabit Transmission Rates", Asia Pacific Conf. on Circuits and Systems APCCAS, ISBN:978-14244-2341-5, 1558-1561 (2008).

[5] D.J. Lockwood, L. Pavesi, “Silicon Photonics II Components and Integration", Topics in App. Phys., 119, 75-77 (2011).

[6] S. Stopiński, M. Malinowski., R. Piramidowicz, M.K. Smit, X.J.M. Leijtens, "Data readout system utilizing photonic integrated circuit", Nucl. Instrum. Methods Phys. Res. A, 725, 183186 (2013).

[7] M.C. Gupta, J. Ballato, The Handbook of Photonics, Second Edition, CRC Press, 2007

[8] M.S. Bakir, J.D. Meindl, Integrated Interconnect Technologies for 3D Nanoelectronic Systems, Artech House (2009).

[9] A.K. Goel, High-Speed VLSI Interconnections, IEEE Press, John Wiley \& Sons, (2007).

[10] A.G. Kirk, D.V. Plant, M.H. Ayliffe, M. Chateauneuf, F. Lacroix, "Design rules for highly parallel free-Space optical Interconnects”, IEEE J. Selected Topics in Quantum Electronics, 9 (2), 531-547 (2003).

[11] A. Tuantranont, V.M. Bright, J. Zhang, W. Zhang, J.A. Neff, Y.C. Lee, "Optical beam steering using MEMS-controllable microlens array", Sensors and Actuators A-Physical 91 (3), 363-372 (2001). 
[12] E. Bisaillon, D. F. Brosseau, T. Yamamoto, M. Mony, E. Bernier, D. Goodwill, D. V. Plant, and A. G. Kirk, "Free-space optical link with spatial redundancy for misalignment tolerance", Photon. Techn. Lett., 14 (2), 242-244 (2002).

[13] G. Guzowski, Z. Lisik, G. Tosik, E. Ciupa, "OM4 bend insensitive multi-mode fibers' usefulness for MCM integration”, Mat. Scien. and Engi. B, 177, 1367-1372 (2012).

[14] B. Dhoedt, R. Baets, P. Van Daele, P. Heremans, J. Van Campenhout, J. Hall, R. Michalzik, A. Schmid, H. Thienpont, R. Vounckx, A. Neyer, D.C. O’Brien, J. Van Koetsem “Optically interconnected integrated circuits to solve the CMOS interconnect bottleneck", IEEE Conf. Electronic Components and Technology, 992-998 (1998).

[15] S. Lis, R. Dylewicz, J. Myśliwiec, A. Miniewicz, S. Patela, "Application of flowable oxides in photonics", Materials Science-Poland, 26 (1), 189-194 (2008).

[16] X. Zhang X., H. Lu, A.M. Soutar. "Development of Planar Optical Waveguides using UV-Patternable Hybrid Sol-gel Coating", Simtech Technical Report (2003).

[17] R.S. Romaniuk, "Instrumentation optical fibres for wave transformation, signal processing, sensors, and photonic functional components, manufactured at Białystok University of Technology in Dorosz Fibre Optics Laboratory", Bull. Pol. Ac.: Tech., 62 (4), 607-618 (2014).

[18] Y. Ishii, S. Koike, Y. Arai, Y. Ando, "SMT-Compatible Large-Tolerance "OptoBump" Interface for Interchip Optical Interconnections”, IEEE Transactions On Advanced Packaging, 26 (2), 122-127 (2003).

[19] A. Kern, S. Paul, D. Wahl, A. Hein, R. Rosch, W. Schwarz, R. Michalzik, "6 Gbit/s Full-Duplex Multimode Fiber Link with Monolithic VCSEL-PIN Transceiver Chips”, ECOC Technical Digest, 1-3 (2011).

[20] Y. Urino, T. Shimizu, M. Okano, N. Hatori, M. Ishizaka, T. Yamamoto, T. Baba, T. Akagawa, S. Akiyama, T. Usuki, D. Okamoto, M. Miura, M. Noguchi, J. Fujikata, D. Shimura, H. Okayama, T. Tsuchizawa, T. Watanabe, K. Yamada, S. Itabashi, E. Saito,
T. Nakamura, Y. Arakawa, "First Demonstration of High Density Optical Interconnects Integrated with Lasers, Optical Modulators and Photodetectors on a Single Silicon Substrate", ECOC Technical Digest, 1-3 (2011).

[21] L. Brusberg, H. Schroder, M. Queisser, K-D. Lang, "Single-mode Glass Waveguide Platform for DWDM Chip-to-Chip Interconnects", 62nd Electronic Components and Technology Conference (ECTC), 1532-1539 (2012).

[22] F. Schwierz, "Graphene transistors", Nature nanotechnology 5, 487-496 (2010).

[23] T. Osuch, P. Gasior, K. Markowski, K. Jedrzejewski, "Development of fiber Bragg gratings technology and their complex structures for sensing, telecommunications and microwave photonics applications", Bull. Pol. Ac.: Tech., 62 (4), 627-633 (2014).

[24] J. Tong, A. Liu, H. Lv, X. Yi, Q. Li, X. Wang, Y. Ding., "Performances Comparison of Ball Lenses Having Gradient Refractive Index Distribution and Homogeneous Medium", I Symposium on Photonics and Optoelectronic (SOPO), 1-4 (2010).

[25] Y-H. Huang, C-C. Yang, T-C. Peng, F-Y. Cheng, M-C. Wu, Y-T. Tsai, C-L. Ho, I-M. Liu, C-C. Hong, C-C. Lin et al., "10-Gb/s InGaAs p-i-n Photodiodes With Wide Spectral Range and Enhanced Visible Spectral Response", Photon. Tech. Lett., 19 (5), 339-341 (2007).

[26] F.E. Doany, C.L. Schow, C.W. Baks, D.M. Kuchta, P. Pepeljugoski, L. Schares, R. Budd, F. Libsch, R. Dangel, F. Horst, B.J. Offrein, J.A. Kash, "160 Gb/s Bidirectional Polymer-Waveguide Board-Level Optical Interconnects Using CMOS-Based Transceivers", Transactions On Advanced Packaging, 32 (2), 345-359 (2009).

[27] MXC Press Release, "MXC multi-fiber optical interconnect platform: New, ultra-high density, connector hardware design compatible with PRIZM® MT expanded beam ferrules", (2014).

[28] J.C. Baker, D.N. Payne, "Expanded-beam connector design study", Appl. Optics, 20, 2861 (1981).

[29] Lambda Research website (OSLO EDU software): http://secure. lambdares.com/education/oslo_edu/(access 24.10.2104). 